\title{
The first Korean case of a newborn with 3p26 microdeletion and $5 q 35$ microduplication inherited from paternal balanced translocation
}

\author{
Jin A Jang ${ }^{1 \oplus}$, Young Bae Sohn²,*(e) Jang Hoon Lee ${ }^{1 \oplus}$, and Moon Sung Park ${ }^{1 \oplus}$ \\ ${ }^{1}$ Department of Pediatrics, Ajou University Hospital, Ajou University School of Medicine, Suwon, Korea \\ ${ }^{2}$ Department of Medical Genetics, Ajou University Hospital, Ajou University School of Medicine, Suwon, Korea
}

\begin{abstract}
Genetic imbalances are a major cause of congenital and developmental abnormalities. We report the first case of a $3 p 26$ microdeletion and 5q35.2q35.3 microduplication in a newborn with multiple congenital anomalies evaluated using chromosomal microarray analysis (CMA) and fluorescence in situ hybridization (FISH). The patient was born at 30 weeks and 2 days of gestation with a body weight of $890 \mathrm{~g}$. He had symmetric intrauterine growth restriction, microcephaly, facial dysmorphism (hypertelorism, blepharophimosis, mild low-set ears, high-arched palate, and micrognathia), and right thumb polydactyly. Echocardiography revealed an atrial septal defect and patent ductus arteriosus. Furthermore, CMA revealed a concurrent microdeletion in $3 p 26$ and a microduplication in $5 q 35.2 q 35.3$. FISH analysis showed that these genetic changes resulted from a translocation mutation between chromosomes 3 and 5. The patient's mother had mild intellectual disability, short stature, and facial dysmorphism, while his father had a normal phenotype. However, parental FISH analysis revealed that the asymptomatic father carried a balanced translocation of chromosomes $3 \mathrm{p} 26$ and 5q35. CMA and FISH tests are useful for diagnosing neonates with multiple congenital abnormalities. Further parental genetic investigation and proper genetic counseling are necessary in cases of chromosomal abnormalities inherited from parental balanced translocations.
\end{abstract}

Key words: Congenital abnormalities, Fluorescence in situ hybridization, Microarray analysis, Genetic translocation, Gene deletion, Chromosome duplication.

\section{Introduction}

Genetic imbalances are a major cause of congenital and developmental abnormalities such as dysmorphic features, mental retardation, developmental delays, and multiple congenital anomalies [1]. Chromosomal abnormalities are a group of genetic diseases caused by chromosomal rearrangements such as deletions, duplications, and inversions of unique genomic seg- ments in specific regions of chromosomes.

Children with microdeletions of the $3 p 26$ chromosomes are known to exhibit low birth weights, feeding problems, hypotonia, and polydactyly [2,3]. Microduplication of the $5 q 35$ chromosome, also known as reversed Sotos syndrome, results in the creation of an additional copy of the NSD 1 gene, which is involved in brain development. This syndrome is characterized by growth retardation, developmental delay, intellectual

Received: 23 February 2021, Revised: 12 April 2021, Accepted: 21 April 2021, Published: 30 June 2021

${ }^{*}$ Corresponding author: Young Bae Sohn, M.D., Ph.D. (iD https://orcid.org/0000-0002-4664-1941

Department of Medical Genetics, Ajou University Hospital, Ajou University School of Medicine, 164 WorldCup-ro, Yeongtong-gu, Suwon 16499, Korea.

Tel: +82-31-219-4522, Fax: +82-31-219-4521, E-mail: ybsohn@ajou.ac.kr

Conflict of interest: The authors declare that they do not have any conflicts of interest.

(ㄷ) This is an open-access article distributed under the terms of the Creative Commons Attribution Non-Commercial License (http://creativecommons.org/licenses/by-nc/4.0/) which permits unrestricted non-commercial use, distribution, and reproduction in any medium, provided the original work is properly cited.

(c) Copyright 2021 by the Korean Society of Medical Genetics and Genomics 
disability, feeding difficulties, and micrognathia, according to the Orphanet Report Series in 2021, there are only 30 published cases of 5 q35 microduplications worldwide [4-6].

While the clinical features of each chromosomal abnormality have been previously elucidated, no cases of patients with chromosomal abnormalities in both genotypes have been reported.

Here we report the clinical and genetic characteristics of the first Korean case of concurrent $3 p 26$ microdeletion and 5q35.2q35.3 microduplication in a newborn with multiple congenital anomalies evaluated using chromosomal microarray analysis (CMA) and fluorescence in situ hybridization (FISH).

\section{Case}

The patient was born at 30 weeks and 2 days of gestation by emergency cesarean section, due to fetal distress, with a birth weight of $890 \mathrm{~g}$ (3rd percentile), a height of $33.6 \mathrm{~cm}$ ( $<3 \mathrm{rd}$ percentile), and a head circumference of $24.6 \mathrm{~cm}$ (3rd percentile). The patient's APGAR scores were 2 and 4 at 5 and 10 minutes, respectively. He exhibited facial dysmorphism, including a small anterior fontanelle, hypertelorism, blepharophimosis, mild lowset ears, high-arched palate, and micrognathia, as well as polydactyly of the right thumb (Fig. 1) and right inguinal hernia. He was the first child of non-consanguineous Korean parents. His mother was the first gravidity, parity and she had no abortion

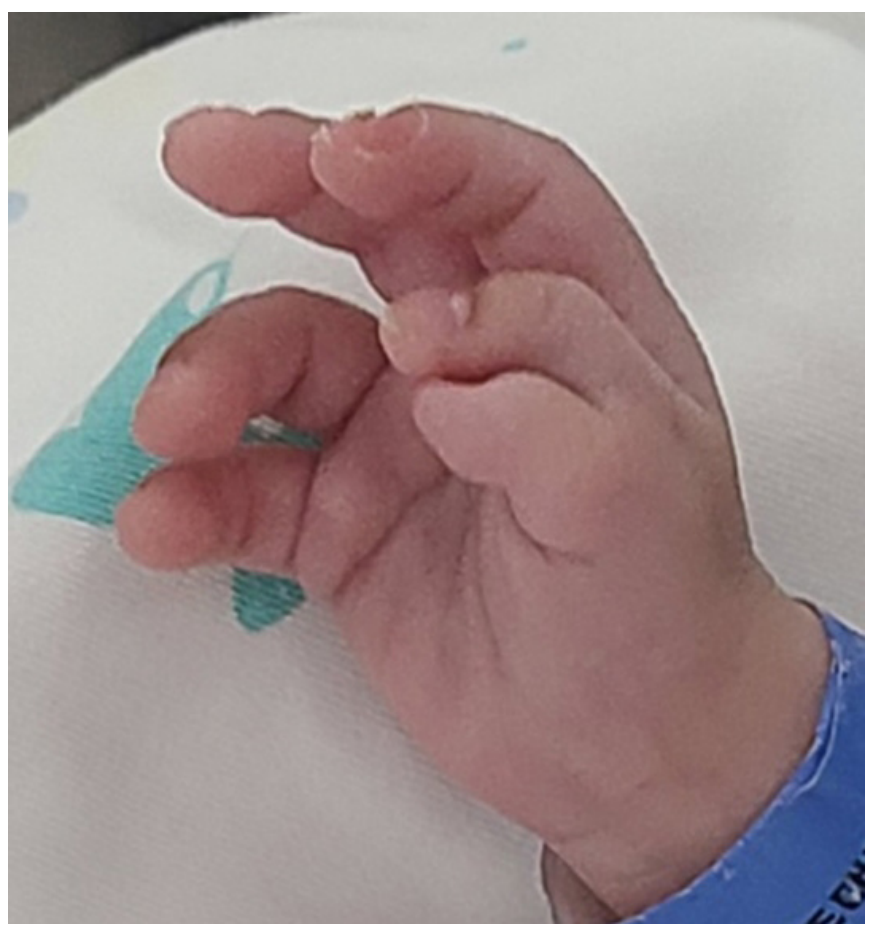

Fig. 1. The patient's right thumb polydactyly. history. His mother had mild intellectual disability, short stature $(140 \mathrm{~cm})$ and mild facial dysmorphism similar to the patient (diamond-shaped face with a narrow forehead, wide zygomatic bone, hypertelorism, and micrognathia). His father had a normal phenotype. His parents had no special family history.

The patient was admitted to the neonatal intensive care unit (NICU) for prematurity and evaluation of congenital anomalies. He required mechanical ventilation at birth due to the absence of respiratory effort after positive-pressure ventilation. Furthermore, the patient had feeding difficulties and recurrent vomiting and thus required tube feeding. Echocardiography at birth showed a $3.2 \mathrm{~mm}$ of atrial septal defect and a $3.2 \mathrm{~mm}$ patent ductus arteriosus that closed spontaneously by 16 days of age. Brain ultrasound was performed at 7 days of age and showed mild hydrocephalus and increased periventricular echogenicity. There were no changes noted in follow-up brain ultrasound until 42 days of age. Upper abdominal ultrasound was performed at 8 days of age, and no specific abnormalities in the gastrointestinal tract and hepatobiliary system were found. Renal ultrasound was performed at 7 and 21 days of age and showed bilateral renal pelvic dilatation. The right and left anteroposterior renal pelvic diameters were $1.9 \mathrm{~mm}$ and $3.1 \mathrm{~mm}$, respectively.

Conventional chromosomal analysis and CMA were performed for the genetic evaluation of symmetric intrauterine growth restriction and multiple congenital anomalies. Chromosomal analysis was performed according to standard protocols. A metaphase G-banding study showed no apparent structural aberrations showing a normal male karyotype $(46, X Y)$ in all 20 cells examined (Fig. 2). This cytogenetic finding does not eliminate a possibility of gene defect, mosaicism and minute or

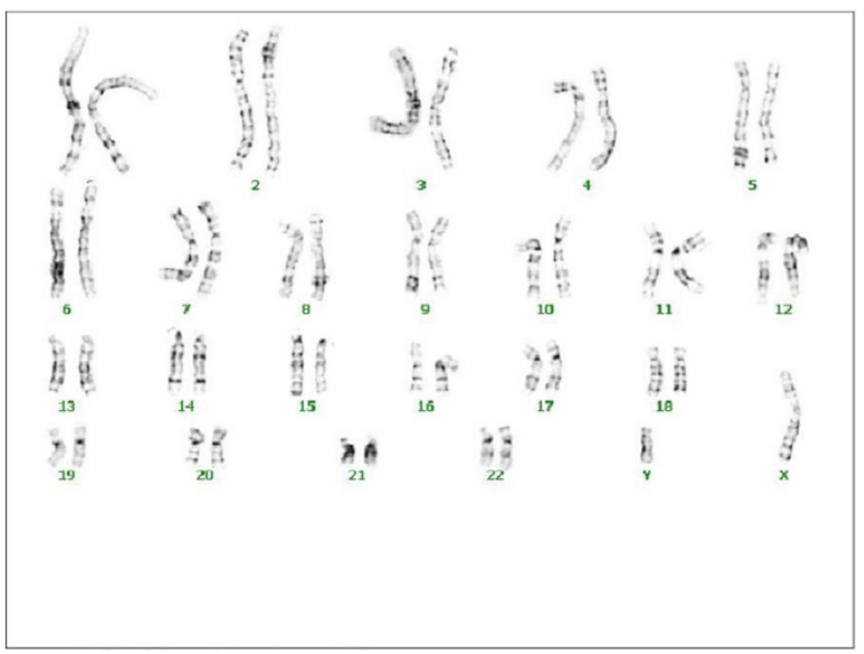

Fig. 2. The patient's karyotype results. 
subtle structural chromosomal aberration. Conventional chromosomal analysis was not performed on his parents, because the patient's karyotype result was normal. CMA with whole blood of the patient was performed with Cytoscan DX Assay using genome build hg 19. An approximately 7.3 Mb deletion was identified in 3p26.3p26.1 (61,891-7,379,955) and a 5.8 Mb duplication was found in 5q35.2q35.3 (174,909,679-180,719,789); both were classified as pathogenic copy number variants (CNVs) (Fig. 3). Considering the possibility that the patient's microdeletion and microduplication were caused by translocation between chromosomes 3 and 5, FISH analyses were performed on both the patient and his parents. Interphase and metaphase preparations from the patient's peripheral lymphocytes were performed following the standard protocol. The results of the patient's FISH analysis confirmed that both CNVs resulted from the translocation of the terminal ends of the $3 p$ and $5 p$ chromosomes (Fig. 4). Furthermore, FISH analysis of interphase and metaphase cells from the patient's father showed a reciprocal balanced translocation between chromosomes 3 and 5 (46, XY t[3:5] [p26.2;5q35.2] ish t[3:5] [p26.2:5q35.2]) (Fig. 5). Although the patient's mother showed clinical features similar to those of the patient (mild intellectual disability, short stature, and facial dysmorphism), her FISH analysis had normal results (46, XX ish 3p26.2, 5q35.2q35.3) (Fig. 6). An additional CMA test for the

A.

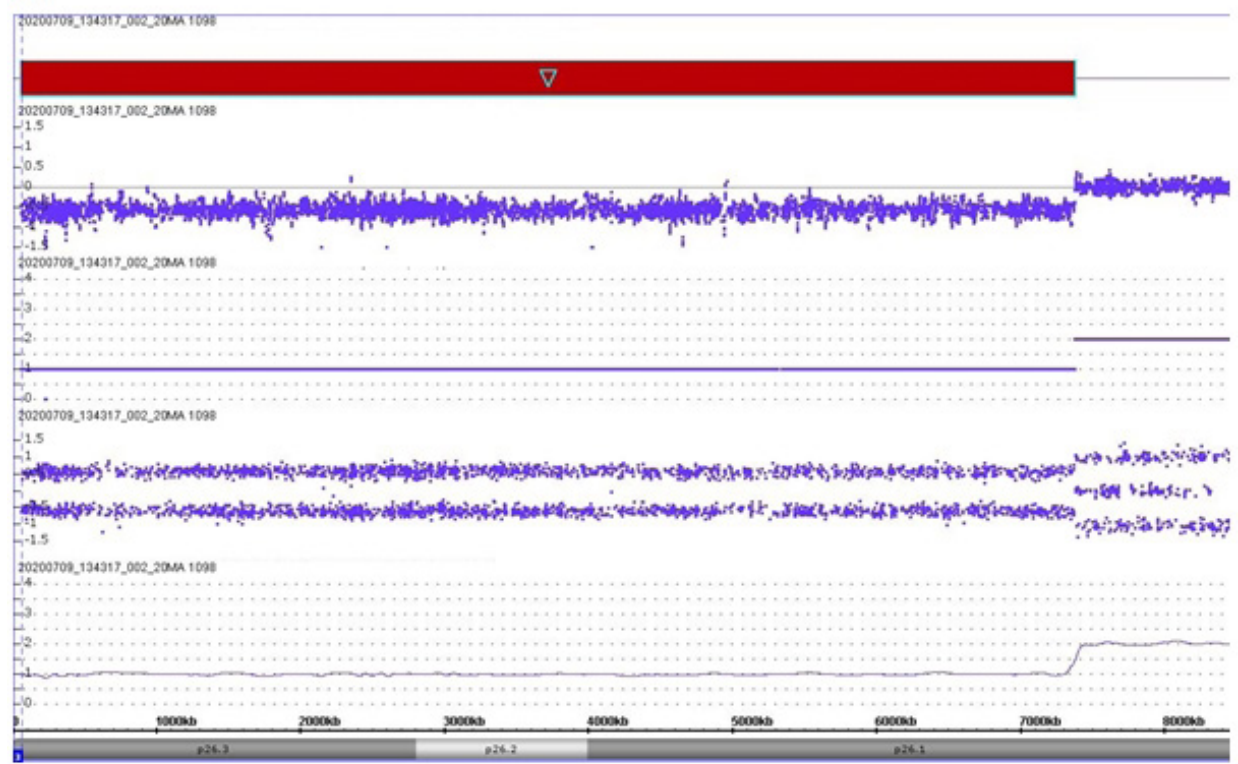

B.

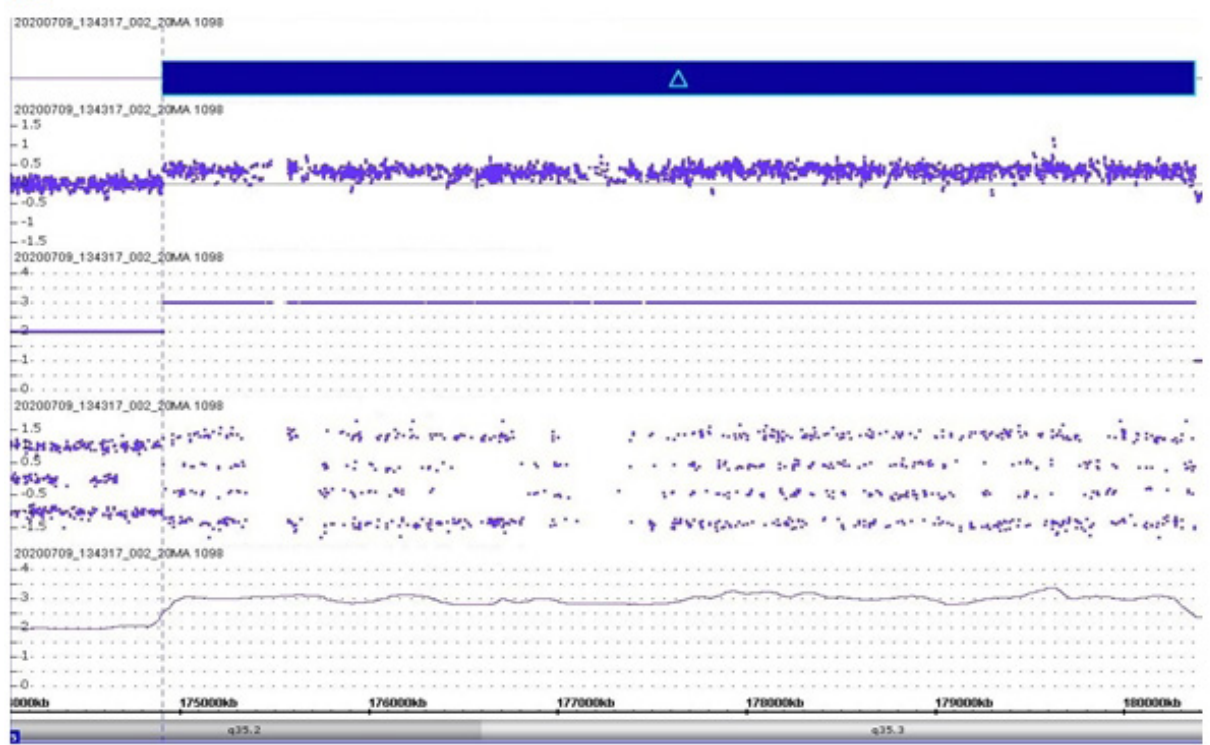

Fig. 3. The patient's chromosomal microarray analysis results. (A) The red bar indicates the 7.3 Mb deletion in 3p26.3p26.1. (B) The blue bar indicates the $5.8 \mathrm{Mb}$ duplication in 5q35.2q35.3. 
A.

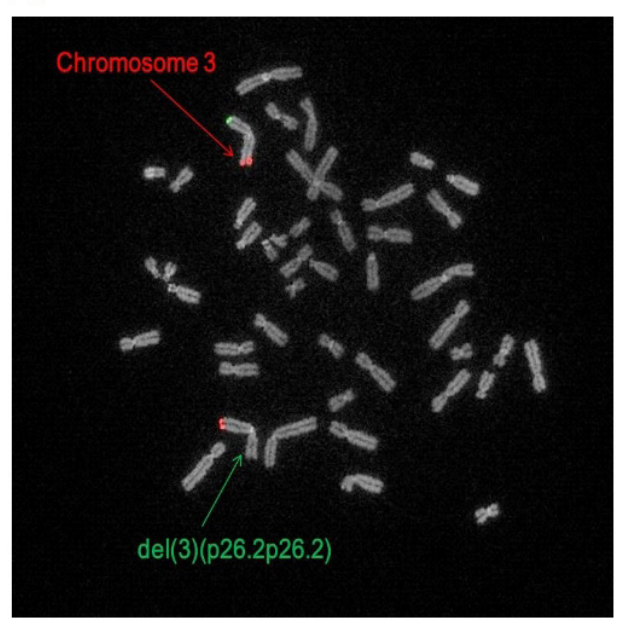

B.

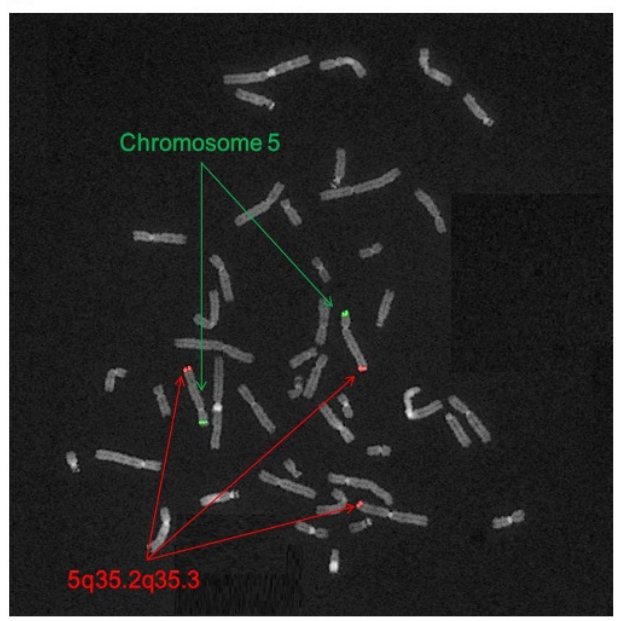

B.
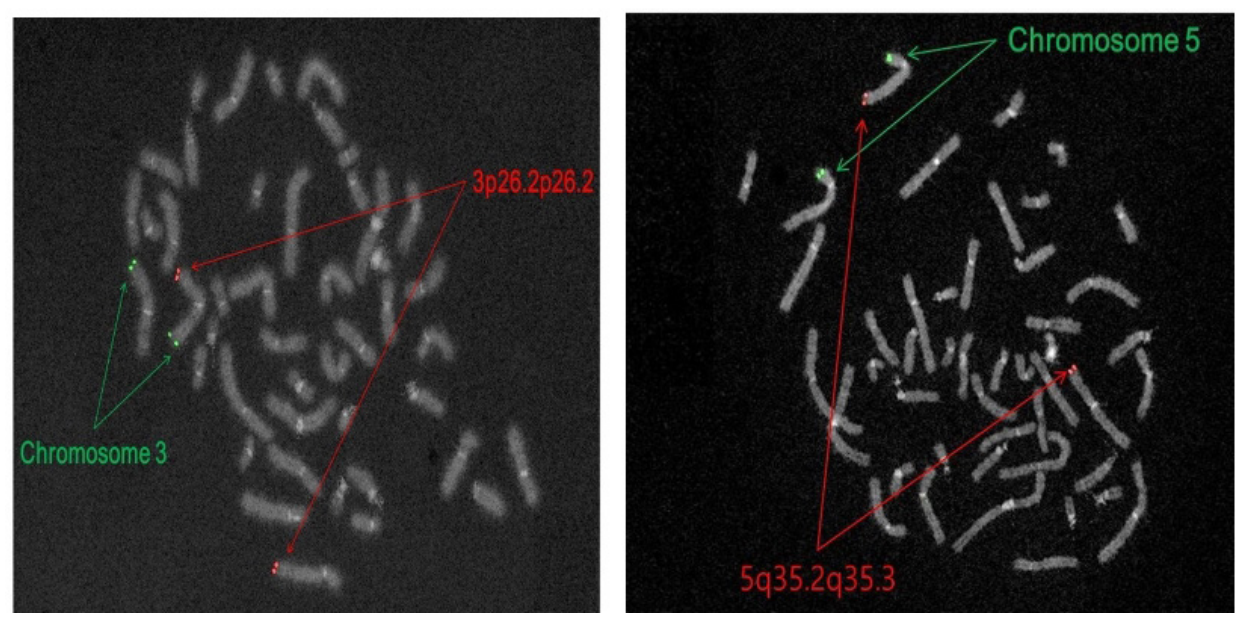

B.

A.

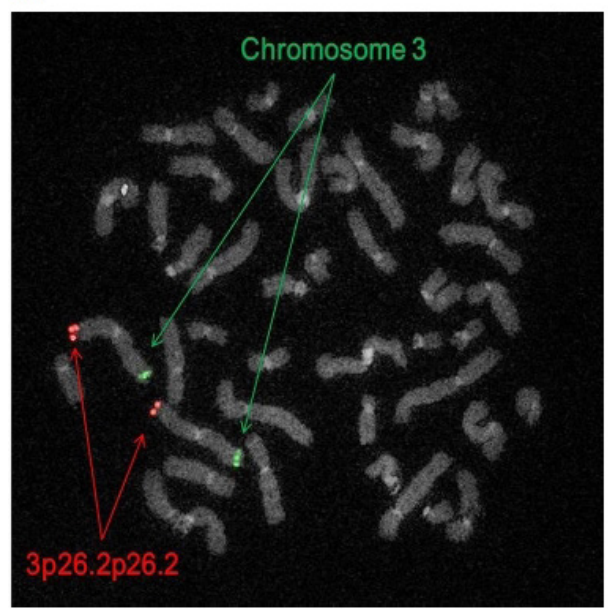

Fig. 4. Fluorescence in situ hybridization (FISH) analysis of the patient. (A) FISH analysis results using a $3 q$ subtelomeric probe (red) and a 3 p26.2 probe (green) showed the deletion of 3p26.2. (B) FISH analysis results using a $5 p$ subtelomeric probe (green) and a $5 q 35.2 q 35.3$ probe (red). The presence of three red signals suggests that the microduplication of $5 q 35.2 q 35.3$ was not interstitial and resulted from chromosomal translocation.

Fig. 5. Fluorescence in situ hybridization (FISH) analysis of the patient's father. FISH analysis results using a $3 q$ subtelomeric probe (green) with a $3 p 26.2$ probe (red) showed the balanced translocation of $3 p 26.2(A)$, and a $5 p$ subtelomeric probe (green) with a 3p26.2 probe (red) showed the balanced translocation of $5 \mathrm{q} 35.2 \mathrm{q} 35.3$ (B).

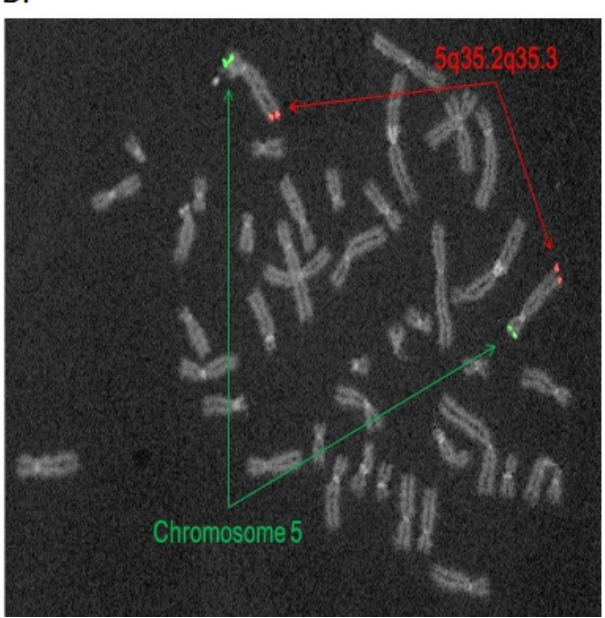

Fig. 6. Fluorescence in situ hybridization (FISH) analysis of the patient's mother. FISH analysis results using a $3 q$ subtelomeric probe (green) with a $3 p 26.2$ probe (red) showed 3p26.2 in its normal location on chromosome $3(A)$, and a $5 p$ subtelomeric probe (green) with a $5 q 35.2 q 35.3$ probe (red) showed $5 q 35.2 q 35.3$ in its normal location on chromosome 5 (B). 
mother also reported normal results.

During the patient's stay in the NICU, he was successfully weaned from mechanical ventilation at 12 days of age, and oxygen support was stopped at 110 days of age. However, he was still noted to have feeding difficulties and required tube feeding and administration of omeprazole and probiotics. Oral feeding was possible at around 100 days of age, and he was eventually discharged from the NICU at 126 days of age. Upon discharge, he had a weight of $2,745 \mathrm{~g}(<3 \mathrm{rd}$ percentile), a height of $47.5 \mathrm{~cm}$ ( $<3 \mathrm{rd}$ percentile), and a head circumference of $32.2 \mathrm{~cm}(<3 \mathrm{rd}$ percentile). He was also noted to have stridor due to laryngomalacia. The patient's development was regularly monitored at the outpatient clinic. His last follow-up consult was when he was 6 month of age (corrected age of 114 days) during which he had a weight of $3.5 \mathrm{~kg}(<1 \mathrm{st}$ percentile), a height of $54.1 \mathrm{~cm}(<1 \mathrm{st}$ percentile), and a head circumference of $33.6 \mathrm{~cm}(<1$ st percentile). The patient's developmental milestones were evaluated at 6 months of chronologic age and were found to be delayed by 2 months. The patient could pay attention to faces and make gurgling sounds but could not control his head and did not demonstrate social smile. Brain magnetic resonance imaging was performed at 120 days of age and showed no remarkable findings. Corrective surgery for polydactyly and inguinal hernia was scheduled at 1 year of age.

\section{Discussion}

We report the first Korean case of 3p26 microdeletion and $5 q 35.2 q 35.3$ microduplication in a patient who was evaluated using CMA and FISH due to multiple congenital anomalies.

The first Korean case of $3 p$ deletion syndrome [7] was previously reported. The low birth weight (53.8\%), hypertelorism (51.9\%), low set ears (59.6\%) and polydactyly (34.6\%) observed in this patient are consistent with previously reported cases of 3p26 chromosome microdeletion (Table 1) $[2,3,7]$. He had low birth weight (46.7\%), microcephaly (26.7\%), flat philtrum (86.7\%), thin upper lip (73.3\%) which are also common findings in previously reported cases of $5 q 35$ microduplication $[4,5,8]$. However, the facial dysmorphisms (small anterior fontanelle, hypertelorism, blepharophimosis, and high arched palate) found in this patient have not been reported previously. In different with preivious case of $5 q 35$ duplication, he had no long face and no long nose (Table 2) [5].

Early diagnosis of genetic disorders through chromosomal testing is helpful in predicting prognosis, guiding, management, and facilitating genetic counseling. It is important to perform
Table 1. Frequency of clinical manifestations in 51 previous cases of $3 p$ deletion and in the present case of $3 p$ deletion and $5 q$ duplication

\begin{tabular}{|c|c|c|c|}
\hline Feature & $\begin{array}{c}\text { Affected } \\
\text { frequency } \\
(n=51)\end{array}$ & $\begin{array}{l}\text { Status in the } \\
\text { presented } \\
\text { case }(n=1)\end{array}$ & $\begin{array}{l}\text { Total (\%) } \\
(n=52)\end{array}$ \\
\hline Triangular face & 11 & - & 11 (21.2) \\
\hline Microcephaly & 22 & + & $23(44.2)$ \\
\hline Flat occiput & 10 & - & $10(19.2)$ \\
\hline $\begin{array}{l}\text { Forehead } \\
\text { abnormality }\end{array}$ & 12 & + & $13(25.0)$ \\
\hline Epicanthal fold & 18 & - & $18(34.6)$ \\
\hline Hyperteloism & 26 & + & $27(51.9)$ \\
\hline $\begin{array}{l}\text { Short palpebral } \\
\text { fissure }\end{array}$ & 12 & - & $12(23.1)$ \\
\hline Ptosis & 16 & - & $16(30.8)$ \\
\hline Synophrys & 12 & - & $12(23.1)$ \\
\hline Nose abnormality & 38 & - & $38(73.1)$ \\
\hline Long philtrum & 34 & - & $34(65.4)$ \\
\hline High arched palate & 15 & + & $16(30.8)$ \\
\hline Cleft palate & 4 & - & $4(7.7)$ \\
\hline Micrognathia & 25 & + & $26(50.0)$ \\
\hline Preauricular pit & 10 & - & 10 (19.2) \\
\hline Low set ears & 30 & + & 31 (59.6) \\
\hline Ear malformation & 26 & - & $26(50.0)$ \\
\hline Low birth weight & 27 & + & $28(53.8)$ \\
\hline $\begin{array}{l}\text { Psychomotor } \\
\text { retraction }\end{array}$ & 41 & - & $41(78.8)$ \\
\hline Growth retardation & 37 & + & $38(73.1)$ \\
\hline Epilepsy & 13 & - & $13(25.0)$ \\
\hline Short neck & 8 & - & $8(15.4)$ \\
\hline Syndactyly & 5 & - & $5(9.6)$ \\
\hline Clinodactyly & 11 & - & 11 (21.2) \\
\hline Polydactyly & 17 & + & $18(34.6)$ \\
\hline Sacral dimple & 12 & - & $12(23.1)$ \\
\hline Hypotonia & 21 & - & $21(40.4)$ \\
\hline $\begin{array}{l}\text { Congenital heart } \\
\text { disease }\end{array}$ & 15 & + & $16(30.8)$ \\
\hline $\begin{array}{l}\text { Genito-urinary tract } \\
\text { abnormality }\end{array}$ & 15 & + & $16(30.8)$ \\
\hline $\begin{array}{l}\text { Gastro-intestinal } \\
\text { abnormality }\end{array}$ & 7 & - & $7(13.5)$ \\
\hline Hearing impairment & 12 & - & $12(23.1)$ \\
\hline
\end{tabular}

+ , presented in this case; -, not presented this case.

Data from the article of Cuoco C et al. (Orphanet J Rare Dis 2011;6:12), Fernandez TV et al. (Am J Med Genet A 2008;146A:2746-52), Lee HJ et al. (J Genet Med 2014;11:36-9) [2,3,7].

chromosomal studies in children with multiple congenital anomalies, unexplained growth retardation, or failure to thrive [1,9-12]. The CMA test can detect very small duplications and deletions even when genetic abnormalities are not detectable by conventional karyotyping $[1,13,14]$. However, while CMA 
Table 2. Frequency of clinical manifestations in 14 previous cases of $5 q 35.2 q 35.3$ microduplication syndrome and in the present case of $3 p$ deletion and $5 q$ duplication

\begin{tabular}{lccc}
\hline \multicolumn{1}{c}{ Feature } & $\begin{array}{c}\text { Affected } \\
\text { frequency } \\
(\mathrm{n}=14)\end{array}$ & $\begin{array}{c}\text { Status in the } \\
\text { presented } \\
\text { case }(\mathrm{n}=1)\end{array}$ & $\begin{array}{c}\text { Total }(\%) \\
(\mathrm{n}=15)\end{array}$ \\
\hline $\begin{array}{c}\text { Short staure } \\
\text { (<10th percentile) }\end{array}$ & 6 & + & $7(46.7)$ \\
$\begin{array}{l}\text { Microcephaly } \\
\text { (<3rd percentile) }\end{array}$ & 3 & + & $4(26.7)$ \\
\hline $\begin{array}{l}\text { Low birth weight } \\
\text { (<10th percentile) }\end{array}$ & 6 & + & $7(46.7)$ \\
\hline $\begin{array}{l}\text { Long face } \\
\text { Short palpebral fis- } \\
\text { sures }\end{array}$ & 10 & - & $10(66.7)$ \\
\hline Epicanthic folds & 9 & - & $9(60.0)$ \\
\hline Periorbital fullness & 10 & - & $4(26.7)$ \\
\hline Telecanthus & 2 & - & $2(13.3)$ \\
\hline Strabism & 4 & - & $4(26.7)$ \\
\hline Prominent nose & 9 & + & $10(66.7)$ \\
\hline Long nose & 5 & - & $5(33.3)$ \\
\hline Flat philtrum & 12 & + & $13(86.7)$ \\
\hline Thin upper lip & 10 & + & $11(73.3)$ \\
\hline Polydactyly & 0 & + & $1(6.7)$ \\
\hline Brachydactyly & 3 & - & $3(20.0)$ \\
\hline Camptodactyly & 2 & - & $2(13.3)$ \\
\hline Seizures & 2 & - & $2(13.3)$ \\
\hline
\end{tabular}

+, presented in this case; -, not presented this case.

Data from the article of Dikow N et al. (Am J Med Genet A 2013;161A:215866) [5].

can identify the precise amount and position of chromosomal changes from which DNA were deleted or duplicated, it cannot identify whether the segments moved to a different location on the same chromosome or to a different chromosome. FISH enables the detection of balanced translocations using fluorescently labeled DNA fragments that match complementary DNA on the patient's chromosomes. Furthermore, FISH allows the determination of the precise location of specific genetic abnormalities $[12,15,16]$. In this case, CMA detected the presence of microdeletions and duplications, while FISH showed that these CNVs resulted from the translocation of chromosomes 3 and 5 .

The patient and his mother demonstrated similar phenotypes. The patient had symmetric intrauterine growth restriction and had right thumb polydactyly, hypertelorism, and mild low set ears, while his mother had mild intellectual disability, short stature, and facial dysmorphism. The patient's father had a normal phenotype. In general, people with similar dysmorphisms have similar chromosomal abnormalities. Therefore, we hypothesized that the patient inherited his genotype from his mother. How- ever, parental genetic analysis identified that his asymptomatic father carried a balanced translocation of the terminal ends of chromosomes $3 p$ and $5 q$. Therefore, in patients with chromosomal translocations, parental genetic investigation is needed even if the parents have a normal phenotype.

Identification of balanced paternal translocations allows for proper genetic counseling to be provided to the family. Prenatal genetic diagnostic procedures, such as chorionic villi sampling, are required when the patient's parents have a second child.

In conclusion, CMA and FISH are useful for diagnosing neonates with multiple congenital abnormalities. Further parental genetic investigations and proper genetic counseling are necessary in cases of chromosomal abnormalities inherited from parental balanced translocations. This report may contribute to the generation of knowledge on rare chromosomal anomalies.

\section{Authors' Contributions}

Conception and design: JHL, YBS. Acquisition of data: JAJ. Analysis and interpretation of data: JAJ. Drafting the article: JA, YBS. Critical revision of the article: YBS, JHL. Final approval of the version to be published: JAJ, YBS, JHL, MSP.

\section{References}

1. Lu X, Shaw CA, Patel A, Li J, Cooper ML, Wells WR, et al. Clinical implementation of chromosomal microarray analysis: summary of 2513 postnatal cases. PLoS One 2007;2:e327.

2. Cuoco $C$, Ronchetto $P$, Gimelli $S$, Béna $F$, Divizia $M T$, Lerone $M$, et al. Microarray based analysis of an inherited terminal 3p26.3 deletion, containing only the CHL1 gene, from a normal father to his two affected children. Orphanet J Rare Dis 2011;6:12.

3. Fernandez TV, García-González IJ, Mason CE, Hernández-Zaragoza G, Ledezma-Rodríguez VC, Anguiano-Alvarez VM, et al. Molecular characterization of a patient with $3 p$ deletion syndrome and a review of the literature. Am J Med Genet A 2008;146A:2746-52.

4. Franco LM, de Ravel T, Graham BH, Frenkel SM, Van Driessche J, Stankiewicz $\mathrm{P}$, et al. A syndrome of short stature, microcephaly and speech delay is associated with duplications reciprocal to the common Sotos syndrome deletion. Eur J Hum Genet 2010;18:258-61.

5. Dikow N, Maas B, Gaspar H, Kreiss-Nachtsheim M, Engels $H_{1}$ Kuechler $A$, et al. The phenotypic spectrum of duplication 5q35.2-q35.3 encompassing NSD1: is it really a reversed Sotos syndrome? Am J Med Genet A 2013;161A:2158-66.

6. Orphanet. Prevalence and incidence of rare diseases: bibliographic data - diseases listed by decreasing prevalence, incidence or number 
of published cases. [http://www.orpha.net/orphacom/cahiers/docs/ GB/Prevalence_of_rare_diseases_by_decreasing_prevalence_or_ cases.pdf]

7. Lee HJ, Kim JH, Cho JH, Lee BH, Choi JH, Yoo HW. Clinical characterization of a Korean case with 3p25 deletion. J Genet Med 2014;11:36-9.

8. Park S, Lee GW, Koh EH, Kim HY. Unexplained pancytopenia in a patient with 5q35.2-q35.3 microduplication encompassing NSD1: a case report. Int J Hematol Oncol Stem Cell Res 2018;12:260-4.

9. Shaffer $L G$, Kashork CD, Saleki R, Rorem E, Sundin $K$, Ballif BC, et al. Targeted genomic microarray analysis for identification of chromosome abnormalities in 1500 consecutive clinical cases. J Pediatr 2006;149:98-102

10. Schoumans J, Ruivenkamp C, Holmberg E, Kyllerman M, Anderlid BM, Nordenskjöld M. Detection of chromosomal imbalances in children with idiopathic mental retardation by array based comparative genomic hybridisation (array-CGH). J Med Genet 2005;42:699-705.

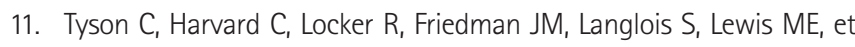
al. Submicroscopic deletions and duplications in individuals with intellectual disability detected by array-CGH. Am J Med Genet A 2005;139:173-85.
12. Jehee FS, Takamori JT, Medeiros PF, Pordeus AC, Latini FR, Bertola DR, et al. Using a combination of MLPA kits to detect chromosomal imbalances in patients with multiple congenital anomalies and mental retardation is a valuable choice for developing countries. Eur J Med Genet 2011;54:e425-32.

13. Coulter ME, Miller DT, Harris DJ, Hawley P, Picker J, Roberts AE, et al. Chromosomal microarray testing influences medical management. Genet Med 2011;13:770-6.

14. Stankiewicz $P$, Beaudet AL. Use of array $C G H$ in the evaluation of dysmorphology, malformations, developmental delay, and idiopathic mental retardation. Curr Opin Genet Dev 2007;17:182-92.

15. Jiang J, Gill BS, Wang GL, Ronald PC, Ward DC. Metaphase and interphase fluorescence in situ hybridization mapping of the rice genome with bacterial artificial chromosomes. Proc Natl Acad Sci U S A 1995;92:4487-91.

16. Pinkel $D$, Landegent J, Collins C, Fuscoe J, Segraves R, Lucas J, et al. Fluorescence in situ hybridization with human chromosome-specific libraries: detection of trisomy 21 and translocations of chromosome 4. Proc Natl Acad Sci U S A 1988;85:9138-42. 